Derecho comercial 


\section{Una clase especial de acciones: las acciones con derecho a veto}

\section{Oswaldo Hundskopf Exebio}

\section{Marco de carácter general}

En la doctrina del derecho societario - y de forma casi unánime- se explica la naturaleza jurídica de las acciones de las sociedades anónimas reconociendo la concurrencia de tres diferentes acepciones o conceptos que necesariamente deben confundirse en uno solo, en una suerte de simbiosis:

a) La acción como parte alícuota del capital social. Esta acepción la ratifica el artículo 82 de la Ley 26887, Ley General de Sociedades (en adelante, LGS), en razón de que el capital social siempre está dividido en acciones que tienen un valor aritmético y son submúltiplos de la cifra de dicho capital. Esta acepción se deriva de la misma naturaleza de los aportes que le dan origen, pues constituyen la prestación de cada accionista, siendo las acciones las contraprestaciones equivalentes, y se deriva también de la necesidad de su cuantificación.

En opinión de Elías Laroza (1999: 194-195), el artículo 82 define a las acciones en su función de representar partes alícuotas del capital social, y su texto desprende los siguientes efectos: 
a. Las acciones se encuentran inseparablemente vinculadas al capital social y responden a aportes efectivos hechos a favor de una sociedad anónima.

b. El capital está dividido en fracciones ideales llamadas acciones.

c. La división del capital en acciones y su adjudicación a los socios, de acuerdo sus respectivos aportes, permite la asignación correcta de los derechos sobre el capital que tiene cada socio y facilita las votaciones, la distribución de utilidades y, en general, el ejercicio de los derechos de cada socio.

d. Siendo cada acción la porción mínima en que se divide el derecho al capital social, ello hace que cada acción sea indivisible.

b) La acción como expresión de la condición o estatus de socio, de la cual se generan un conjunto de derechos y obligaciones como accionista. Dicha condición está expresada en un documento denominado certificado de acciones, o en anotaciones en cuenta, y gracias a dicho estatus se inicia una compleja relación jurídica bilateral con la sociedad. Es importante destacar que como producto de dicha relación nacen derechos y obligaciones recíprocos entre ambas partes, que están debidamente establecidos a lo largo del articulado de la LGS.

c) La acción como título valor y como bien mueble representativo de los derechos del accionista y que, por tal razón, es un instrumento circulatorio y/o documento que es a la vez prueba y certificado de la condición de accionista y de los derechos que le corresponden. Gasperoni ${ }^{1}$ señala que por ser un documento necesario para el ejercicio de los derechos inherentes al estatus del socio - es decir, para que el titular de esos derechos pueda legitimarse-, es indudable que la acción integra la categoría de los títulos valores, pero con características propias. También refiere que es un título formal porque debe contar con las enunciaciones exigidas por la ley o el estatuto; que es un título incompleto, pues todos los derechos inherentes al estatus de socio no están mencionados en el título, sino en el estatuto; y que es un título causal porque se emite de acuerdo con lo que disponen la ley

1 Citado por Beaumont (2003). 
y el estatuto, a los que siempre debe referirse, y contiene una declaración de verdad y su emisión generalmente es obligatoria, por lo que no es en estricto un acto unilateral. En el caso de la LGS, que solo admite acciones nominativas, representadas en certificados o en anotaciones en cuenta, las acciones vienen a ser títulos valores sui géneris o especiales a los cuales se les incorporan los derechos de carácter corporativo, siendo títulos de participación social, y son a la vez prueba certificada de la condición de accionista. Ahora bien, las acciones no son simples títulos, sino mucho más que eso, pues son en realidad el resultado de la conjunción de las tres acepciones conceptuales señaladas. Sucede a menudo que en algunas legislaciones societarias - como ocurrió en nuestra ley anterior, ya derogada - se le reconoce una excesiva importancia a la acción como título, siendo en nuestro caso los artículos 110, 111, 112 y 145, entre otros, de la Ley 16123, modificada por el Decreto Legislativo 311, claros ejemplos de las distorsiones y trastornos que ocasionó una regulación fragmentada e incompleta, bajo la cual el ejercicio de los derechos esenciales de los accionistas se supeditan y condicionan a la formalidad y tenencia de los títulos físicos, cuando estos solo son la expresión de la acción propiamente dicha, en cuya naturaleza jurídica concurren y se concentran necesariamente tres acepciones conceptuales.

Ahora bien, el artículo 51 de la LGS consolida el carácter nominativo obligatorio de las acciones y, por tanto, mantiene la prohibición de emitirlas al portador, proveniente del histórico Decreto Supremo 287-68$\mathrm{HC}$, que innovó en nuestro país el régimen del impuesto a la renta. Si bien las acciones al portador están proscritas, la Ley General de Sociedades, Ley 16123, modificada por el Decreto Legislativo 311, las mencionaba de manera expresa en sus artículos 78, inciso 7; 80, inciso 5; 107 y 130; y aludía a ellas también en sus artículos 111, 112, 145 y 223. Corrigiendo tales errores, la LGS ha eliminado toda referencia o alusión a las acciones al portador.

Las normas que regulan las acciones contenidas en la LGS diferencian tres actos: en primer lugar, el de la creación de acciones, pues son derechos; en segundo lugar, el acto de su suscripción y pago; y, en tercer lugar, el acto de la emisión propiamente dicha. Esta diferenciación constituye una innovación técnica normativa muy interesante.

En cuanto al primer acto, el artículo 83 de la LGS establece que las 
acciones se crean en el pacto social o, con posterioridad, por acuerdo de la junta general, debiendo hacerse la anotación correspondiente en la matrícula de acciones según lo estipula el artículo 92. Cabe resaltar que el segundo párrafo del artículo 83 establece, con meridiana claridad, que es nula la creación de acciones que concedan el derecho a recibir un rendimiento sin que existan utilidades distribuibles, lo cual significa que en la sociedad anónima tienen que generarse utilidades y sustentarse en estados financieros veraces, como condición insustituible, eliminándose de esta forma la eventual creación de una clase de acciones que garanticen un dividendo anual fijo, independientemente de que la sociedad tenga o no utilidades.

En el mismo orden de ideas, el último párrafo del artículo 83 expresa que puede concederse a determinadas acciones el derecho a un rendimiento, máximo, mínimo o fijo, acumulable o no, siempre sujeto a la existencia de utilidades distribuibles, lo cual propicia o permite la creación de una clase especial de acciones, tema que será comentado más adelante, al igual que el dividendo preferencial de las acciones con derecho a voto a que se refiere el artículo 97, igualmente supeditado o condicionado a la existencia de utilidades distribuibles.

La identificación precisa del acto jurídico de la creación de acciones ha hecho posible la creación de las acciones en cartera originarias, con o sin derecho a voto, a que se refiere el artículo 98 de la LGS, lo cual es una consecuencia positiva de esta interesante innovación técnica normativa. Este tipo de acciones, si no son suscritas y pagadas en, por lo menos, una cuarta parte de su valor nominal, no pueden ser emitidas $y$, por tanto, no generan los derechos que les son inherentes.

Respecto a la suscripción de acciones, esta es una fase en que las personas - naturales o jurídicas - las hacen suyas, con lo que se convierten en sus titulares y se comprometen a pagar, cuando menos, la cuarta parte de cada una. Así, el artículo 52 dispone que para la constitución de la sociedad es necesario que su capital social esté suscrito totalmente - lo cual significa que todas sus acciones representativas estén suscritas, es decir, tengan un titular- y que las acciones, cuando menos, estén pagadas en una cuarta parte; regla que se aplica no solo a la constitución de sociedades, sino también a los aumentos de capital. Ahora bien, el monto pagado por cada acción suscrita debe aparecer en forma obligatoria en el estatuto social, conforme al inciso 5 del artículo 55, y la diferencia entre lo pagado y el valor nominal de las acciones suscritas da lugar a los denominados dividendos pasivos, los que se deben cubrir en la forma y el 
plazo previstos por el pacto social o, en su defecto, por el acuerdo de la junta general. Si ello no se hiciere, los accionistas incurrirán en mora automática, sin necesidad de intimación, según lo dispone el artículo 78 de la LGS.

Conforme al artículo 84, después de la suscripción y pago de las acciones en, por lo menos, la cuarta parte de su valor nominal, corresponde emitirlas, salvo en el caso de quienes hacen aportes no dinerarios, para los cuales el artículo 76 de la LGS prevé un procedimiento de revisión y/o ratificación por el directorio, en cuyo caso las acciones no se emitirán hasta que transcurran los plazos respectivos. Esta disposición, también, se aplica tanto a la constitución de sociedades como a los aumentos de capital.

Ahora bien, los derechos que corresponden a las acciones emitidas son independientes de si se encuentran representadas por certificados provisionales o definitivos, anotaciones en cuenta o en cualquier otra forma permitida por la ley; y, a no ser que sus titulares hayan incurrido en mora por el no pago de los dividendos pasivos, gozan de todos los derechos aunque no se encuentren totalmente pagadas, independientemente de la oportunidad en la que hayan sido emitidas o pagadas, salvo disposición contraria del estatuto o acuerdo de la junta general. Si bien la norma contenida en el inciso 2 del artículo 230 se refiere exclusivamente a los dividendos, arribamos a la categórica conclusión que antecede interpretando dicha norma en concordancia con el artículo 79, referido a los efectos de la mora, los que, como se puede advertir, son variados y de diverso contenido.

En lo que respecta a los derechos fundamentales del accionista, la doctrina del derecho societario los considera una tercera categoría de derechos, distinta de los derechos reales o los derechos de crédito; una especie de derechos personales corporativos. Tales derechos corresponden o son inherentes solo a las acciones emitidas, conforme se ha destacado, y son independientes de si estas se encuentran representadas por certificados provisionales o definitivos, anotaciones en cuenta o cualquier otra forma permitida por la ley; y su contenido y alcances dependerán de si se trata de acciones con derecho a voto o sin derecho a voto, o de si se trata de acciones comunes o preferenciales.

Según se infiere del artículo 95 de la LGS - que prácticamente repite lo dispuesto en el artículo 109 de la Ley 16123, modificada por el Decreto Legislativo 311-, los derechos mínimos de los titulares de las 
acciones con derecho a voto son cinco: uno de contenido político-personal, como el derecho de intervenir con voz y voto en las juntas de accionistas, y cuatro de contenido económico-patrimonial. Esos cinco derechos son:

- Participar en el reparto de utilidades y en el patrimonio neto resultante de la liquidación. Adviértase que este es uno de los muchos artículos de la LGS que se refieren específicamente al "patrimonio neto". ${ }^{2}$

- Intervenir y votar en las juntas generales o especiales, según corresponda.

- Fiscalizar la gestión de los negocios sociales en la forma establecida en la ley y en el estatuto. A esos efectos, el accionista tiene los mecanismos para convocar a la junta, así como el derecho de información ratificado en el artículo 130 de la LGS.

- Ser preferido, con las excepciones y en la forma prevista en la ley, para la suscripción de acciones en el caso de aumento de capital social y en los demás casos de colocación de acciones, así como en la suscripción de obligaciones u otros títulos convertibles o con derecho a ser convertidos en acciones.

- Derecho de separación, en los casos previstos por la ley o en el estatuto.

Por su parte, el artículo 96 de la LGS consigna los derechos que poseen los titulares de las acciones sin derecho a voto, debiéndose destacar que en ningún caso accederán con ellas a este derecho, a diferencia de lo establecido en la Ley 26356, ya derogada. Es decir, el accionista que opta por suscribir y/o adquirir acciones sin derecho a voto está dispuesto a cambiar sus derechos políticos por un derecho económico especial, para lo cual se ha establecido un dividendo preferencial y, además, una prioridad en la distribución del haber social. No obstante, en la LGS también se ha considerado un conjunto de derechos a favor de estos accionistas: el de recibir información semestral; el de separación en los

2 Ver Hundskopf (2001: 47-58). 
casos previstos en la ley o en el estatuto; el de impugnación de los acuerdos que lesionen sus derechos; el de suscripción preferente de acciones con o sin derecho a voto, dependiendo de que se den los diversos supuestos establecidos en el mencionado artículo 96; o el derecho a la suscripción de obligaciones u otros títulos convertibles o con derecho a ser convertidos en acciones.

En lo que respecta a la transmisibilidad o transferencia de acciones, el artículo 93 de la LGS se refiere a su obligatoria comunicación a la sociedad para su anotación en la matrícula de acciones, pero introduce una innovación: cuando las acciones estén representadas por certificados, para acreditar su transmisión basta la entrega a la sociedad del certificado con la constancia de la cesión a nombre del adquiriente o por cualquier otro medio escrito, debiendo la sociedad aceptar la cesión cuando la efectúe quien aparezca en la matrícula como propietario de la acción, con lo cual se facilita la negociación de los títulos y su circulación. Ahora bien, si hubiere dos o más cesiones, la sociedad puede exigir que las sucesivas transferencias sean acreditadas por otros medios. Al respecto, cabe decir que la versión original del artículo 93 de la LGS se refería al "endoso" en lugar de la "cesión", lo cual fue enmendado por la tercera disposición modificatoria de la Ley de Títulos Valores, Ley 27287, pues fue un error utilizar, para títulos nominativos, el sistema de circulación de los títulos a la orden.

Asimismo, en el artículo 101 de la LGS se han regulado las limitaciones a la libre transmisibilidad de las acciones, las cuales son obligatorias para la sociedad cuando estén contempladas en el pacto social, en el estatuto o se originen en convenios entre accionistas y terceros, que hayan sido notificados a la sociedad. Dichas limitaciones se deberán inscribir en la matrícula de acciones y en los respectivos certificados. Cuando la LGS se refiere a las limitaciones que se originan en un convenio, se está refiriendo a los universalmente conocidos como convenios de sindicación de acciones, relacionados con el ejercicio de un derecho de preferencia dentro de grupos de accionistas, los cuales, con la ley anterior, eran simples convenios privados en los que la sociedad no se involucraba con quien los hacía, ni los hacía exigibles, situación que ha cambiado, pues en el artículo 8 de la actual LGS hay un reconocimiento oficial de la validez y eficacia de estos convenios, obligándose a la sociedad a que los haga respetar.

Como novedad, se ha regulado en el artículo 101 la prohibición temporal -adoptada por un accionista o por acuerdo de junta general a 
plazo determinado, que no puede exceder de diez años prorrogables antes del vencimiento por periodos no mayores- de transferir y afectar acciones, con su inmediata separación en clases, agrupándose en una de ellas a quienes votaron a favor del acuerdo, sin que rijan en este caso los requisitos de la ley o del estatuto para la modificación de este último. Los términos y condiciones de la prohibición temporal deben ser anotados en la matrícula de acciones, en los certificados, anotaciones en cuenta o en el documento que evidencie la titularidad de la respectiva acción.

Con relación a la transmisión de acciones afectas a obligaciones adicionales, el artículo 102 de la LGS ha establecido que, a no ser que el pacto social, el estatuto o el convenio con terceros establezcan lo contrario, la transmisión de acciones cuya titularidad lleve aparejada el cumplimiento de obligaciones para con la sociedad, otros accionistas o terceros, deberá contar, según corresponda, con la aceptación de la sociedad, de los accionistas o terceros a favor de quienes se haya pactado la obligación, salvo que el obligado garantice solidariamente su cumplimiento, si la naturaleza de la obligación lo permite.

\section{Valor nominal de las acciones}

Cuando el artículo 82 de la LGS señala que las acciones representan partes alícuotas del capital social y que todas tienen el mismo valor nominal, ello significa, por un lado, que no pueden coexistir en una misma sociedad anónima acciones de diferente valor nominal, aunque sean de diferentes clases; $y$, por otro, que tampoco pueden existir acciones sin valor nominal. Siendo así, fijar un valor nominal desde la constitución de la sociedad resulta una norma imperativa y de observancia obligatoria y lleva a que la suma de todas las acciones equivalga a la cifra del capital social, dado que su valor constituye un submúltiplo matemáticamente exacto. La forma como se ha regulado el valor nominal en el artículo 82 de la LGS difiere de la ley anterior, ya derogada, según cuyo artículo 105 - siguiendo el ejemplo español- podían existir clases de acciones diferenciadas o por el valor nominal o por el contenido de derechos, o por ambas cosas a la vez.

Elías Laroza ha comentado las razones del cambio de regulación:

[...] dos han sido los argumentos que determinaron la adopción del cambio por la Comisión Reformadora. El primero, la aplicación prác- 
tica de la LGS anterior demostró en muchos casos la confusión generada por el establecimiento de diversos valores nominales en distintas clases de acciones de la misma sociedad, que originó conflictos en torno al dividendo por acción y a la desproporción en el voto, entre otros temas. El segundo, la interpretación de que esta posibilidad genera una forma indirecta de voto plural. En suma, las disposiciones de la nueva ley no admiten duda en cuanto a la exigencia de la igualdad del valor nominal para todas las acciones de la sociedad, sin excepción alguna (1999: 200).

Como hemos dicho, el valor nominal está directamente vinculado con el capital social y son los fundadores quienes deciden cuál es este último y de qué forma está dividido y representado en partes alícuotas. Es importante destacar que no existe en la LGS ninguna norma que establezca ni un capital social mínimo ni un valor nominal determinado, lo que, en consecuencia, se deja a la voluntad de los fundadores. Sin embargo, para ciertas actividades económicas específicas, reguladas por leyes especiales, sí existe un capital mínimo.

Ahora bien, frente al valor nominal está el valor real de las acciones o valor en libros, que resulta de dividir el "patrimonio neto" entre el número de acciones; el valor de mercado, que resulta de dividir el "valor empresa" entre el número de acciones; y, por último, el valor de cotización para las acciones cotizables en bolsa, que es el promedio de las transacciones en un día o periodo determinado, producto de la oferta y la demanda.

El valor nominal, sin duda, tiene singular importancia, pues es el punto de partida y el referente necesario para contrastarlo con el valor real. Asimismo, el valor nominal y el capital social son los puntos de partida para, a su vez, contrastarlos con el patrimonio neto y el valor empresa. En cuanto al valor de cotización, este es muy sensible y está afecto a factores exógenos y coyunturales que inciden en su fluctuación, pero, en términos generales, tiende a aproximarse más al valor real que al valor nominal.

\section{Clases de acciones}

El artículo 55 de la LGS, referido al contenido que obligatoriamente debe contener el estatuto de una sociedad anónima, establece en su 
inciso 6 la necesidad de señalar, cuando corresponda, las clases de acciones en que está dividido el capital, el número de acciones de cada clase, las características, derechos especiales o preferencias que se establezcan a su favor y el régimen de prestaciones accesorias o de obligaciones adicionales. Ahora bien, esta disposición normativa parte, sin embargo, de un postulado categórico establecido en el artículo 82, según el cual el mismo valor nominal de cada acción da derecho a un voto, con la excepción prevista en el artículo 164 - referida a la elección del directorio por el sistema del voto acumulativo- y las demás contempladas en la ley, que no son otras que las acciones sin derecho a voto, reguladas en el artículo 96.

Dentro de dicho concepto, en el artículo 88 de la LGS se establece de manera complementaria que en una sociedad anónima pueden coexistir clases de acciones que se diferencien por los derechos que correspondan a sus titulares, por las obligaciones a su cargo o por ambas cosas a la vez, pudiendo crearse en la escritura pública de constitución o, posteriormente, por acuerdo de la junta general. Sin embargo, todas las acciones de una clase gozarán de los mismos derechos y tendrán a su cargo las mismas obligaciones, en concordancia con el artículo 86. Reiteramos al respecto la diferencia con la ley anterior, que permitía la diferenciación entre una clase y otra, ya sea en el monto del valor nominal o en el contenido de derechos. Asimismo, se ha normado en el mismo artículo 88 el proceso de eliminación de cualquier clase de acciones y la modificación de los derechos y obligaciones de las acciones de cualquier clase, exigiendo el previo cumplimiento de los requisitos para la modificación de estatutos, la aprobación previa en junta especial de los titulares de las acciones de la clase que se elimine o cuyos derechos y obligaciones se modifiquen, y, en su caso, la aprobación de quienes se vean afectados con dicha decisión, comprendiéndose en ello a la sociedad, otros accionistas o terceros.

Asimismo, el último acápite del artículo 88 posibilita que a través del estatuto se establezcan supuestos para la conversión de acciones de una clase en acciones de otra clase, sin que se requiera un acuerdo de junta general o de juntas especiales, y precisa que solo será necesaria la modificación estatutaria si, como consecuencia de la conversión, desaparece una clase de acciones.

Como ya se ha dicho, en el artículo 86 de la LGS se ha incluido la posibilidad de establecer en el pacto social o en el acuerdo de aumento de capital que los suscriptores, de una parte o de todas las acciones, asuman 
determinadas obligaciones a favor de otros accionistas, de la sociedad o de terceros, adicionales a las de pagar su valor, ya sea nominal o de colocación, lo que también constituye una innovación. Estas obligaciones adicionales podrán ser dinerarias o no, y deberán recaer sobre todas las acciones de la sociedad o sobre todas las acciones de una determinada clase, debiendo constar en los propios certificados, en las anotaciones en cuenta o en cualquier otra forma de representación de esas acciones.

Dichas obligaciones adicionales son independientes del pago de las acciones suscritas, ya sea que se hayan suscrito a la par, bajo la par o sobre la par, gravan directamente a las acciones que suscribe el accionista y, como se ha mencionado, recaen sobre todas las acciones de la sociedad o sobre todas las acciones de una determinada clase. En la práctica, se suelen confundir con las prestaciones accesorias reguladas en el artículo 75, que son obligaciones personales de hacer, no hacer o de dar que asumen los accionistas, independientemente de sus aportes $\mathrm{y}$, por lo tanto, de las acciones que suscriben. Al respecto, es importante tomar en cuenta lo que expresa Artieda Aramburú, quien "considera recomendable que en caso de que los accionistas de una sociedad anónima decidan incluir, ya sea en el pacto social o por acto posterior, prestaciones accesorias, incluyan también las reglas aplicables a la transmisión de las acciones que contengan a dichas prestaciones" (2003: 305).

Beaumont Callirgos (2003: 396), partiendo de la regulación sobre las clases de acciones contenidas en la LGS, hace una interesante clasificación de las acciones:

a) Acciones ordinarias o comunes y acciones preferenciales.

b) Acciones de fundador y acciones ordinarias.

c) Acciones reembolsables.

d) Acciones con derecho a voto y acciones privilegiadas sin derecho a voto.

e) Acciones afectas a obligaciones adicionales.

f) Acciones con derecho exclusivo a suscripción de nuevas acciones, entre otras.

Adviértase que en esta clasificación no se incluyen o no se consideran, ni tampoco en ningún artículo de la LGS, las acciones con derecho 
a veto, también conocidas como acciones doradas o golden shares, cuyas características intentaremos describir en el presente artículo, pero desde ya consideramos que no estarían proscritas o prohibidas en nuestro ordenamiento legal actual, pues integrarían una clase especial de acciones con un derecho muy particular que es el derecho a vetar un acuerdo, de forma tal que sin su aprobación no podría adoptarse este, todo lo cual debe estar específicamente regulado en el estatuto social.

\section{Acciones especiales con derecho a veto}

\subsection{Primeros antecedentes en nuestro país}

En la primera fase del gobierno militar, en un marco legal de transformaciones ideológicas impuestas mediante la aprobación de leyes generales sectoriales y la creación de las comunidades laborales en las principales actividades productivas, se diseñó la opción de constituir sociedades de economía mixta, en las que podrían participar inversionistas privados, junto con el Estado. En el proyecto de norma reguladora que se elaboró con ese propósito y que fue comentado por Lucrecia Maisch von Humboldt (1973: 25), se incluyeron, en su artículo sexto, las acciones con derecho a veto a favor del Estado, para mediante ellas dejar sin efecto o impedir que la junta general de accionistas adoptara acuerdos sin la anuencia o conformidad de estas acciones, con la justificación jurídica de la necesidad de defender los intereses del Estado cuando este se encontrara en posición minoritaria, y en consideración al fin público que perseguían las sociedades de economía mixta.

En cuanto a la constitución de este tipo de sociedades, se exigía la autorización del Estado o de la colectividad pública interviniente, fundamentándose en la necesidad de dejar constancia fehaciente de que su participación obedecía a razones de interés general, en la de señalar la prioridad de la actividad que habría de desarrollar dicha sociedad, y en la cuantía, proporción y modalidad del aporte respectivo.

Respecto a las acciones con derecho a veto, el proyecto las incorporaba en concordancia con la moderna doctrina y la legislación más avanzada de la época, reconociéndolas y estableciéndolas como un mecanismo de defensa de los intereses del Estado, lo que se justificaba por las razones de interés general que motivaban su permanencia como socio. 
Como lo destaca Maisch, esta facultad no era irrestricta, pues de ser así originaría una situación de desequilibrio entre los socios que no solo tornaría muy remota la posibilidad de constituir una sociedad de economía mixta, sino que destruiría las bases y la finalidad de la institución, que no era otra que la armoniosa colaboración entre el sector privado y el sector público en el desarrollo de las actividades de interés general. Por esa razón, en el proyecto se contemplaron cuidadosamente las causales que podían originar el derecho de veto, valiéndose para ello del análisis de la doctrina e inspirándose en normas de las legislaciones francesa, argentina y mexicana.

Maisch advirtió que si el derecho de veto no se regulaba en forma apropiada y equilibrada podía resultar un derecho ilusorio que por la falta de normativa fuese de difícil ejercicio. En el otro extremo, una casuística excesiva podía entorpecer la marcha de la sociedad o producir excesos, razón por la cual el proyecto enumeró taxativamente las causales de veto.

En ese orden de ideas, los dos primeros incisos del artículo 95 del proyecto se referían a operaciones económicas respecto a las cuales el Estado o la colectividad pública interviniente pudiera tener razones para ejercer su derecho de veto, por estimar que dichas operaciones pudieran poner en peligro la estabilidad económica de la sociedad, debiendo destacarse que el monto del diez por ciento de las acciones o de participación en el capital a que se referían los dos citados incisos podía, evidentemente, ser modificado en la ley de creación de cada sociedad en consideración de múltiples factores, como el total del capital social, la cuantía de la participación estatal, la prioridad del objeto social, etc., motivo por el cual resultaba recomendable que en la ley de creación de cada sociedad de economía mixta se analizara cuidadosamente este problema, en relación con los citados factores, a fin de establecer en forma óptima el monto de las operaciones y su relación con el capital social, respecto a las cuales el Estado podía ejercitar el derecho de veto.

La tercera causal que podía originar el veto del Estado se refería a los acuerdos de aumento de capital mediante nuevos aportes o conversión de obligaciones en acciones, pues esas decisiones podrían resultar inconvenientes para el Estado debido a las diversas consecuencias que eventualmente generarían, como por ejemplo, la minimización de la participación del sector público, la pérdida del control de la sociedad y el aumento inconveniente de la influencia del sector privado. 
El cuarto inciso del artículo 95 del proyecto expresaba que el acuerdo de emisión de obligaciones era susceptible de ser vetado por el Estado, debido a que los recursos obtenidos con esa emisión podían conducir a situaciones no convenientes, como un endeudamiento excesivo o una captación de fondos para los cuales no hay utilización inmediata, con el riesgo adicional de una eventual capitalización de esas obligaciones.

Si bien las sociedades de economía mixta se presentaban como una modalidad empresarial interesante, pues promocionaban la participación de la inversión privada, no se conoce que se hayan creado por ley especial y, por tanto, hayan funcionado.

\subsection{Las acciones con derecho a veto y su vinculación con el proceso de privatización}

En el Perú, al igual que en todos los países donde ha habido o hay empresas estatales, se encuentran razones suficientes que justifican la necesidad impostergable de que el Estado deje de actuar como empresario, entre ellas: los resultados económicos y financieros negativos; la inconveniente consolidación de monopolios, oligopolios y privilegios de las empresas estatales, atentatorios contra la libre competencia; la interferencia política en la administración de las empresas; la ineficiencia originada por el sobredimensionamiento del personal laboral; la descapitalización, producto de las pérdidas, que se aprecia en la obsolescencia tecnológica; y la casi nula contribución en la generación de recursos para el Estado.

Conforme se observa en el anexo 1 del estudio Guía para la privatización en el Perú, de Rafael Toledo Segura (1992: 410), los primeros intentos de privatización ocurrieron a partir de 1978, en la segunda fase del gobierno militar, y se reiniciaron en 1986, en el primer gobierno de Alan García. Toledo Segura (1992: 17-18) afirma que las escasas empresas y participaciones estatales privatizadas fueron de pequeñísimo tamaño y que los intentos o anuncios de medianos o grandes procesos de privatización solo fueron ofrecimientos políticos, pues las enormes y continuas pérdidas que alimentaban el déficit fiscal no motivaron el aceleramiento de esos procesos.

Desde marzo de 1991 hasta setiembre del mismo año, el proceso de privatización estuvo regido básicamente por el Decreto Supremo 041-91$\mathrm{EF}$, sobre regulación del proceso de redimensionamiento de la actividad empresarial del Estado. Fue, sin embargo, el Decreto Legislativo 674 -de 
27 de setiembre de 1991, denominado Ley de Promoción de la Inversión Privada en las Empresas del Estado - el que marca un hito en el proceso de privatización, con disposiciones orientadas a promover la inversión privada y el crecimiento de la inversión. Según los considerandos de dicha importante norma legal dictada por el Ejecutivo en uso de las facultades legislativas delegadas por el Congreso mediante la Ley 25327, era necesario crear las condiciones adecuadas para el desarrollo y el crecimiento de la inversión privada en el ámbito de las empresas del Estado, con el objeto de lograr la modernización, el saneamiento y la vigorización de las actividades a su cargo, por lo que resultaba indispensable, por un lado, otorgar a los inversionistas privados las garantías de mecanismos claros y seguros de adquisición de acciones y bienes de empresas del Estado, y, por otro lado, brindar a este último los instrumentos necesarios para una recuperación económica en el más corto plazo, que le permitiera contar con recursos para aplicarlos a la seguridad, la salud, la educación y la infraestructura vial, entre otros destinos.

Conforme al artículo 2 del Decreto Legislativo 674, entre las modalidades por las cuales se promueve el crecimiento de la inversión en el ámbito de las empresas que conforman la actividad empresarial del Estado está la transferencia al sector privado del total o de una parte de las acciones, o de los activos de las empresas estatales. Asimismo, en el párrafo final de dicho artículo se establece que si como consecuencia de esa transferencia el Estado resulta, en forma directa o indirecta, con una participación accionaria minoritaria, sus derechos y obligaciones se regirán exclusivamente por la Ley General de Sociedades. ${ }^{3}$

Más adelante, la Ley 26844 - de 16 de julio de 1997- trajo disposiciones aplicables al proceso de promoción de la inversión privada en las empresas del Estado del sector hidrocarburos. Su artículo 1 estableció que aquel proceso deberá sujetarse a las siguientes disposiciones:

a) El Estado mantendrá una participación minoritaria en el capital social de las empresas, constituida por la propiedad de una o más

3 En la fecha de la dación del Decreto Legislativo 674 - 25 de setiembre de $1991-$ estaba vigente el Decreto Supremo 003-85-JUS, Texto Único Ordenado de la Ley General de Sociedades, aprobado por Decreto Legislativo 311. 
acciones, según lo determine la Comisión de Promoción de la Inversión Privada (Copri).

b) Antes de su transferencia al sector privado, las empresas deben modificar sus estatutos a fin de crear una serie especial de acciones conformada únicamente por una o más acciones cuya propiedad corresponderá al Estado.

Opinamos que en el marco de la Ley General de Sociedades vigente en esa época, a la que se remitió dicha norma, se dispuso la creación a nombre del Estado de una clase especial de acciones, lo cual no contradecía las posibilidades que el propio ordenamiento legal societario permitía, por lo que no era necesario modificarlo, sino tan solo incorporar en el estatuto social de cada sociedad esa clase especial de acciones. Esta es la primera oportunidad en la que se hace expresa mención, en una norma legal, de prerrogativas y atribuciones que les corresponden a dicha clase de acciones.

Su régimen es el siguiente:

1. Para que se transfieran las acciones de esta clase especial se requiere autorización previa otorgada mediante decreto supremo con el voto aprobatorio del Consejo de Ministros.

2. En tanto se mantengan en propiedad del Estado, dichas acciones son inembargables, es decir, no pueden ser objeto de prenda ni usufructo y confieren a su titular los siguientes derechos:

i) Voto determinante en las siguientes decisiones: cierre de la empresa, incorporación de nuevos accionistas mediante cualquier modalidad, reducción de capital, emisión de obligaciones convertibles en acciones, inscripción de cualquier clase de acciones de la empresa en la Bolsa de Valores, cambio de objeto social, transformación, fusión, escisión o disolución de la sociedad y constitución de garantías reales sobre bienes sociales para respaldar obligaciones distintas de las de la propia empresa.

ii) Derecho de elegir cuando menos a un director.

Para que se adopten cualesquiera de los acuerdos referidos a los 
temas mencionados se requiere del voto favorable de esta clase especial de acciones, para lo cual el Estado debe votar la propuesta independientemente, y la decisión alcanzada, de ser desfavorable, impedirá la adopción válida de los acuerdos correspondientes. Adviértase, pues, que constituyen un claro ejemplo de acciones con derecho a veto que hacen imposible la adopción válida de acuerdos de las juntas generales, los cuales tampoco se podrían formalizar y perfeccionar por escritura pública y menos aún inscribirse en el Registro. Es a partir de esta norma legal que se le comienza a llamar a esta clase especial de acciones como "acciones doradas" o "acciones de oro" (golden shares).

3. Las acciones cuyo titular no sea el Estado no pueden transferirse a terceros sin la autorización previa de la junta general adoptada con el voto conforme del titular de la acción o acciones de propiedad del Estado. No deja de ser interesante, en este punto, la obligatoria incorporación al estatuto social de una sociedad anónima - como asunto de competencia de la junta general de accionistas - de la aprobación de las transferencias de acciones de terceros, la que debe contar con la necesaria anuencia de las acciones de esta clase especial a través del voto conforme del titular de estas acciones del Estado; advirtiéndose, además, que si esas transferencias se efectúan contraviniendo lo dispuesto anteriormente, la misma ley señala que serán nulas. Una disposición de esta naturaleza existe, en la actualidad, dentro del marco legal de la sociedad anónima cerrada, pues en el artículo 238 de la LGS se señala que el estatuto puede establecer que toda transferencia de acciones o de acciones de cierta clase quede sometida al consentimiento de la sociedad, que lo expresará mediante acuerdo de junta general adoptable con no menos de la mayoría absoluta de las acciones suscritas con derecho a voto.

Asimismo, el artículo 1 de la Ley 26844 señala que solo procederá la negativa a una propuesta de transferencia de acciones a terceros cuando el Estado considere que la persona natural o jurídica que se propone adquirirlas representa un peligro para la seguridad nacional. Aun cuando no se especifica qué sucede cuando se produce esa denegatoria, a manera de comentario indicamos que en el caso de la sociedad anónima cerrada, la denegatoria del consentimiento a la transferencia determina que la sociedad queda obligada a adquirir las acciones en el precio y condiciones ofertadas. 
Por último, es importante destacar dos últimos aspectos de la Ley 26844. El primero de ellos es que si, previamente, con el voto favorable de las acciones especiales se aprobó la inscripción en la Bolsa de Valores de una determinada clase de acciones, no serán aplicables las restricciones a la incorporación de nuevos socios cuando estos adquieran acciones en rueda de bolsa, pues el Estado ha dado ya su anuencia y conformidad para la inscripción de esta clase de acciones. El segundo aspecto es que el artículo quinto de la Ley 26884 establece que el Poder Ejecutivo, mediante decreto supremo con el voto aprobatorio del Consejo de Ministros, podrá prescindir, por excepción, de la aplicación de este régimen de acciones con derecho a veto cuando se trate de la privatización de empresas de pequeña envergadura, caso en el cual el proceso se rige sólo por lo dispuesto en el Decreto Legislativo 674 y sus normas complementarias.

Poco tiempo después de la dación de la Ley 26844, la Ley 26876 Ley Antimonopolio y Antioligopolio del Sector Eléctrico, de 18 de noviembre de 1997 - comprendió dentro de los alcances de la primera a las empresas de energía eléctrica dedicadas a la generación y/o transmisión y/o distribución de energía.

En lo que concierne al sector hidrocarburos, por aplicación de la Ley 26844 se incorporaron al estatuto social de Petroperú y de Relapasa las acciones con derecho a veto o "acciones doradas". En el sector energético también existen estas acciones, consideradas como "clase C" en los estatutos de Seal, Elsa, Electro Puno, Electro Sur, Egasa, Egesur, Egemsa, Enosa, Hidrandina, Electro Centro, Ensa, Electro Oriente y Electro Ucayali. Absolutamente, en todos los casos, las escrituras públicas de modificación de estatuto, mediante las cuales se crearon esta clase especial de acciones, se inscribieron sin mayores problemas en los registros públicos.

Las acciones doradas se utilizaron en Inglaterra, Francia e Israel, con objetivos variados. En nuestro país, este esquema fue impulsado como un mecanismo para asegurar la participación estatal en ciertos servicios públicos considerados estratégicos, mediante la creación de una clase especial de acciones, lo que se justificaba por razones de seguridad nacional.

Pero regresemos al proceso evolutivo de nuestra legislación. Por Decreto Supremo 061-2002-EF — de 8 de abril del 2002 - se dispuso la transferencia de las acciones de la serie especial de acciones de propiedad del Estado, creadas por la Ley 26844, de las empresas dedicadas a la 
generación y/o transmisión y/o distribución de energía eléctrica, incluidas en el proceso de promoción de la inversión privada a que se refiere el Decreto Legislativo 674, cuando así lo decida la Copri mediante acuerdo expreso. También se dispuso que dicha transferencia se sujetará a las condiciones establecidas para la transferencia de acciones comunes.

Conforme se dijo, las acciones de esta clase especial solo podían transferirse previa autorización otorgada mediante decreto supremo con el voto aprobatorio del Consejo de Ministros, y es esa autorización lo que se otorga con el Decreto Supremo 061-2002-EF. En lo que se refiere al marco legal de las empresas de energía eléctrica, cualquier empresa que cumpla con los requisitos de la Ley de Concesiones Eléctricas tiene derecho a obtener del Estado una concesión de generación, transmisión o distribución, sin estar obligada a otorgar participación en su propiedad al Estado, lo que no concuerda con las restricciones al control de la gestión y a las decisiones que la clase especial de acciones dispone y que originaban una transferencia limitada de la administración.

Ahora bien, el sustento del mencionado decreto supremo fue el Decreto Ley 23118, cuyo artículo 34 considera la energía eléctrica como un servicio público esencial y cuyo artículo 35 dispone que el Estado puede restringir o reorientar las actividades de las empresas dedicadas a la prestación de estos servicios. El mismo decreto supremo, a efectos de incrementar la competencia en los concursos públicos internacionales, consideró conveniente autorizar la transferencia de las acciones que integran la clase especial mencionada.

En el año 2003 se discutió en el pleno del Congreso el proyecto de ley 2483-2001-CR, por el que se pretendía dejar sin efecto el Decreto Supremo 061-2002-EF. Su exposición de motivos señaló que este último contraviene lo establecido en la Ley 26884, pues esta permite, por excepción, solo la transferencia de acciones doradas de las empresas de pequeña envergadura, mientras que el citado decreto supremo autoriza dicha transferencia para todo tipo de empresas eléctricas. El proyecto de ley fue desestimado por, entre otras, las siguientes consideraciones:

i. La Ley 26844, aplicable por expresa remisión de la Ley 26876, permite la transferencia de acciones doradas de las empresas eléctricas; sin embargo, la supedita a la autorización expedida por decreto supremo con el voto aprobatorio del Consejo de Ministros. 
ii. El Decreto Supremo 061-2002-EF no viola la Ley 26844; por el contrario, ejecuta lo dispuesto en el numeral 1 del literal b) del artículo 1 de la referida ley, pues, siendo un decreto supremo expedido con el voto aprobatorio del Consejo de Ministros, autoriza la transferencia de las acciones doradas de las empresas eléctricas, delegando en Proinversión (entidad que sustituyó a la Copri) la potestad de escoger el momento oportuno de hacerla.

iii. El Decreto Supremo 061-2002-EF constituye un acto de administración interna que autoriza la transferencia, al sector privado, de bienes de propiedad estatal, es decir, de las acciones doradas.

Por último, y para concluir con este proceso evolutivo, en el Decreto Legislativo 1031 -de 23 de junio del 2008-, cuyo objeto es promover la eficiencia de la actividad empresarial del Estado, sobre todo en lo que se refiere a sus principios, naturaleza, organización, conducción, funciones, gestión, recursos y su vinculación con los sistemas administrativos del Estado, se ha delimitado el ámbito empresarial del Estado ratificando que dicha actividad se desarrolla en forma subsidiaria y sustentada en razón del alto interés público o manifiesta conveniencia nacional, en cualquier sector económico, sin que ello implique una reserva exclusiva a favor del Estado o se impida el acceso de la inversión privada.

En cuanto a las formas en que se desarrolla la actividad empresarial de Estado, el artículo 4 del Decreto Legislativo 1031 menciona las siguientes:

a) Empresas del Estado de accionariado único, donde el Estado tiene el control íntegro de la junta de accionistas.

b) Empresas del Estado con accionariado privado, en las que el Estado tiene la propiedad mayoritaria de las acciones y, por tanto, ejerce el control mayoritario de la junta de accionistas, existiendo accionistas minoritarios no vinculados al Estado.

c) Empresas del Estado con potestades de derecho público, para el ejercicio de sus funciones.

No deja de ser relevante el párrafo final de ese artículo 4, donde se puntualiza que el accionariado estatal minoritario en empresas privadas 
no constituye actividad empresarial del Estado y se sujeta a las disposiciones de la LGS y demás normas aplicables a dichas empresas. En ese orden de ideas, habiéndose modificado los estatutos de todas las sociedades anónimas de los sectores hidrocarburos y energía eléctrica en los que se han creado acciones clase $\mathrm{C}$ - también denominadas "acciones con derecho a veto" o "acciones doradas" - , y encontrándose inscritos en Registros Públicos, en nada se altera el normal funcionamiento de esas sociedades, pues de manera unánime la doctrina y las legislaciones societarias reconocen al pacto social y al estatuto como los instrumentos fundamentales que rigen la vida de la sociedad. Para Joaquín Garrigues - reconocido tratadista español-, el estatuto es como la norma constitucional que rige la vida interna de la sociedad en todo aquello que no constituya derecho legal imperativo.

\section{Reflexiones finales}

1. En ciertos procesos de privatización se recurrió a la creación de una clase especial de acciones (clase $\mathrm{C}$ ), con atribuciones y prerrogativas especiales, entre ellas el derecho a veto, acciones a las cuales se las conoce como "acciones doradas" o "acciones de oro" (golden shares).

2. Si bien la creación de esta clase de acciones nació de una iniciativa del Estado expresada en normas legales específicas, en razón de la oportunidad en que se dieron se remitieron a la LGS en ese momento vigente (Decreto Legislativo 311 y su Texto Único Ordenado, aprobado por Decreto Supremo 03-85-JUS), y en tales ocasiones se consideró que no era necesario incorporar nuevas normas en el ordenamiento legal societario que hicieran viable la creación de dicha clase de acciones, pues ya se encontraba prevista la opción de contar, dentro de una misma sociedad, con diferentes clases de acciones que se distingan por el contenido de derechos, debido a lo cual podían coexistir acciones comunes y acciones privilegiadas. Las opciones con derecho a veto son, según nuestro modo de ver, un tipo de acciones privilegiadas.

3. Lo más destacable del proceso evolutivo que se ha descrito es el reconocimiento de la fuerza que tiene el estatuto social dentro de una sociedad anónima como instrumento fundamental que rige la vida de esta. Debido a ello, para canalizar la creación de las acciones con derecho a veto lo primero que debía hacerse, y se hizo, era disponer la modificación del estatuto, formalizar y perfeccionar el acuerdo de 
la junta general por escritura pública y, por último, inscribirlo en el registro.

4. En general, el esquema de funcionamiento de esta clase especial de acciones fue traído del derecho societario europeo, específicamente, del Reino Unido. Son muchos los países de la Unión Europea que en los últimos quince años han experimentado procesos de privatización y en algunos de ellos se han creado esta clase especial de acciones.

5. Las acciones especiales con derecho a veto fueron, en realidad, una técnica de privatización utilizada en aquellos supuestos en que se estimó necesario compatibilizar una operación de transferencia de una empresa pública a la esfera privada, con la debida protección de los intereses nacionales. Estas acciones, que tras los procesos de privatización dejan como titular al Estado, llevan aparejadas unos derechos especiales que tornan imprescindible el consentimiento de su titular para que la empresa pueda adoptar válidamente determinadas decisiones que se consideran relevantes para los intereses nacionales.

6. La experiencia europea es muy fértil en la utilización de esta clase especial de acciones. Es abundante la bibliografía y la casuística ventilada ante el Tribunal de Justicia de la Unión Europea, como tampoco son pocas las objeciones doctrinarias hechas a sus diversas presentaciones y/o modalidades. Es, sin duda, un proyecto muy interesante llevar adelante un trabajo de investigación sobre el particular. Revisadas muy someramente algunas de las principales legislaciones de la Comunidad Económica Europea en lo que se refiere a esta clase especial de acciones, se advierte que sus características no son iguales ni tampoco son similares los supuestos en los que se puede utilizar, siendo, en algunos casos, más amplia la incorporación de limitaciones o restricciones.

7. Por último, al margen del proceso histórico en nuestro país, y en relación con la creación de esta clase especial de acciones dentro de los procesos de privatización, las preguntas finales que debemos plantear son:

i) Dentro del marco legal existente a raíz de la vigencia de la LGS, que en principio es imperativo, ¿hay una flexibilización que, sin llegar a ser propia de un sistema dispositivo, permita crear esta 
clase especial de acciones a efectos de continuar con procesos de privatización que han quedado truncos? Esta es una inquietud frente a la cual nuestra posición es positiva.

ii) ¿Sería posible crear una clase de acciones con derecho a veto solo para un grupo de accionistas, en virtud de que su participación en el accionariado resulta conveniente y estratégica en función del objeto social que desarrolla la sociedad? Esta es otra inquietud frente a la cual, también, nuestra respuesta es positiva. La ley no prohíbe la posibilidad de esa creación, y esta no choca con nuestro marco legal porque - debido a la tendencia actual hacia una flexibilización y reconocimiento de la autonomía de la voluntad, y en aplicación del principio de la libertad de pactos- los propios socios pueden acordar la creación y coexistencia de clases de acciones, una de las cuales puede ser la que agrupa a las acciones privilegiadas con derecho a veto. 


\section{Bibliografía}

ARTIEDA ARAMBURÚ, Rafael (2003). "Las prestaciones accesorias". Tratado de derecho mercantil. Tomo I: Derecho societario. Lima: Gaceta Jurídica.

BEAUMONT CALLIRGOS, Ricardo (2003). "Las acciones de la sociedad anónima". Tratado de derecho mercantil. Tomo I: Derecho societario. Lima: Gaceta Jurídica.

ELÍAS LAROZA, Enrique (1999). Derecho societario peruano. Tomo I. Trujillo: Normas Legales.

HUNDSKOPF, Oswaldo (2001). "Apuntes sobre la relación capital social y patrimonio neto en la sociedad anónima". Ius et Praxis 32. Lima: Revista de la Facultad de Derecho de la Universidad de Lima.

MAISCH VON HUMBOLDT, Lucrecia (1973). Sociedades de economía mixta. Lima: Universidad Nacional Mayor de San Marcos. Dirección Universitaria de Biblioteca y Publicación.

TOLEDO SEGURA, Rafael (1992). Guía para la privatización en el Perú. Lima: Fundación M.J. Bustamante de la Fuente. 